\title{
OLIGOHYDRAMNIOS IN THIRD TRIMESTER AND PERINATAL OUTCOME
}

\author{
Babar Shrikant A1, Shanbhag S. $D^{2}$
}

${ }_{1}^{1}$ Assistant Professor, Department of Obstetrics and Gynaecology, Rajarshi Chhatrapati Shahu Maharaj Government Medical College and Hospital, Kolhapur, Maharashtra.

2Professor, Department of Obstetrics and Gynaecology, Rajarshi Chhatrapati Shahu Maharaj Government Medical College and Hospital, Kolhapur, Maharashtra.

\section{ABSTRACT}

\section{BACKGROUND}

The purpose of this study is to assess the effects of oligohydramnios on perinatal outcome, especially in third trimester of pregnancy.

\section{METHODS}

This is an intrapartum observational study conducted in Obstetrics and Gynaecology Department of Rajarshi Chhatrapati Shahu Maharaj Government Medical College and Hospital, Kolhapur, Maharashtra, from October to December 2015 for a period of 120 days. In this study, 70 singleton pregnant females with gestational age from $32-42$ weeks with less amniotic fluid index (AFI $<8 \mathrm{~cm})$ were analysed for perinatal outcome. Data were expressed as number (Percentage). Proportion test was performed for comparison, $\mathrm{P}$ value $<0.05$ was taken as level of significance.

\section{RESULTS}

Women with oligohydramnios were significantly associated with an abnormal intrapartum Foetal Heart Rate (FHR), i.e. foetal distress, meconium stained fluid, Apgar score less than 7 or NICU admission. Also subjects with AFI $5.0 \mathrm{~cm}$ or less had a higher rate of caesarean section for foetal distress.

\section{CONCLUSIONS}

Although, in our population antepartum oligohydramnios alone is not predictive of adverse perinatal outcome as measured by low APGAR score and NICU admission, gestational age, severity of oligohydramnios and associated IUGR are other important criteria for perinatal outcome, yet this may be reflective of the aggressive antepartum and intrapartum management in these patients.

\section{KEYWORDS}

Oligohydramnios, Perinatal Outcomes, IUGR, AFI.

HOW TO CITE THIS ARTICLE: Shrikant BA, Shanbhag SD. Oligohydramnios in third trimester and perinatal outcome. J. Evolution Med. Dent. Sci. 2016;5(41):2511-2513, DOI: 10.14260/jemds/2016/586

\section{INTRODUCTION}

Oligohydramnios is decreased amniotic fluid volume below 200 mL.(1) Amniotic fluid volume can be measured by different methods, of which most commonly used is Amniotic Fluid Index (AFI) on ultrasonography. Phelan (1987) defined oligohydramnios as AFI $<5 \mathrm{~cm}$ ( $5^{\text {th }}$ centile). ${ }^{(2,3)}$ Incidence is $12 \%$ at $40-41$ weeks and $25 \%$ after 41 weeks. Absence of fluid pocket of $2-3 \mathrm{~cm}$ in depth or amniotic fluid volume $<500 \mathrm{~mL}$ at 32-36 weeks, then oligohydramnios is suspected. Women with oligohydramnios are more likely to have abnormal or nonreactive FHR tracings, increased incidence of foetal distress and thus an increased incidence of caesarean sections.(4) Oligohydramnios is also the leading indication for labour induction. Labour induction increases caesarean delivery, particularly for primiparous women with an unripe cervix.(5) Oligohydramnios is associated with a high rate of pregnancy complications and increased perinatal morbidity and mortality.

Financial or Other, Competing Interest: None.

Submission 30-01-2016, Peer Review 27-02-2016,

Acceptance 03-03-2016, Published 21-05-2016.

Corresponding Author:

Dr. Babar Shrikant A,

A/P: Khochi,

Hatkanangale Taluk,

Kolhapur Dist-416110,

Maharashtra.

E-mail:dr.shrikantbabar@gmail.com

DOI: $10.14260 /$ jemds $/ 2016 / 586$
Thus, AFI assessed antepartum or intrapartum would help to identify women who need increased antepartum surveillance for pregnancy complications. Some studies show that amniotic fluid index is poor predictor of perinatal outcome.(6) However, ante-partum and intra-partum AFI assessment is helpful to assess perinatal complications. $(7,8)$

\section{MATERIALS AND METHODS}

It is intrapartum observational study conducted in Obstetrics and Gynaecology Department of Rajarshi Chhatrapati Shahu Maharaj Government Medical College and Hospital, Kolhapur, Maharashtra, from October to December 2015 for a period of 120 days.

Patients with oligohydramnios at more than 32 weeks of gestational age were included in this study. Oligohydramnios was diagnosed with the help of ultrasonography done intrapartumally. Ultrasonography showing AFI $<8 \mathrm{~cm}$ were included in the study. Other inclusion criteria were patients having Premature Rupture of Membranes (PROM), Preterm Premature Rupture of Membranes (PPROM) more than 12 hours, patients diagnosed as Intrauterine Growth Restriction (IUGR) antenatally along with oligohydramnios.

Patients with any medical complications like gestational diabetes mellitus, hypertension, heart disease or any obstetric complications like preeclampsia, eclampsia, multiple pregnancies, antepartum haemorrhage, pregnancy with anomalous baby, pregnancy with previous caesarean section were excluded from this study. 
On admission, foetal cardiotocography was done for each patient. Variable decelerations, late deceleration or prolonged bradycardia was an indicator of Foetal Distress. Partographic monitoring was done of each labour.

Quantity and the colour of liquor was assessed at the time of rupture of membrane, intrapartum and at the time of LSCS.

\section{RESULTS}

Mean age of the patients was $26.14 \pm 4.13$ years. Among 70 pregnant women, borderline oligohydramnios (AFI 5-8 cm) was $27 \%$ and moderate-to-severe oligohydramnios (AFI $<5 \mathrm{~cm}$ ) was $73 \%$. Mean AFI was $3.97 \pm 1.83 \mathrm{~cm}$. About $49 \%$ patients were delivered at less than 37 completed weeks. Out of 70 women studied, preterm labour is seen in $38.5 \%$ of patients; postdatism in $4.2 \%$.

In most of the cases (54\%), delivery was by caesarean section and 34\% caesarean sections were because of foetal distress. Table 5 shows that caesarean section was significantly higher in severe oligohydramnios group than in borderline oligohydramnios group, which is statistically significant $(\mathrm{P}<0.05)$. Neonatal Death (NND) is more in low Apgar score $(<9 / 10)$; however, this difference is not statistically significant $(\mathrm{p}>0.05)$. Perinatal outcome was poor (4 NND and 3 IUFD) in preterm group ( $<37$ weeks), which is statistically significant $(\mathrm{P}<0.05)$. Better perinatal outcome is seen in 36-40 weeks group.

\begin{tabular}{|c|c|c|}
\hline Mode of Delivery & No. & Percentage \\
\hline VAGINAL & 32 & 45.71 \\
\hline LSCS & 38 & 54.28 \\
\hline \multicolumn{2}{|c|}{ Table 1: Mode of Delivery } \\
\hline
\end{tabular}

\begin{tabular}{|c|c|c|}
\hline Indications of LSCS & No. & Percentage \\
\hline Prolonged PROM & 3 & 4.28 \\
\hline $\begin{array}{c}\text { Severe oligohydramnios } \\
\qquad \mathrm{AFI}<3 \mathrm{~cm}\end{array}$ & 6 & 8.57 \\
\hline $\begin{array}{l}\text { Foetal distress/Non- } \\
\text { reactive NST }\end{array}$ & 24 & 34.28 \\
\hline $\begin{array}{l}\text { Severe IUGR with } \\
\text { oligohydramnios }\end{array}$ & 3 & 4.28 \\
\hline Thick meconium & 2 & 2.85 \\
\hline \multicolumn{3}{|c|}{ Table 2: Incidence of Indications for LSCS } \\
\hline
\end{tabular}

\begin{tabular}{|c|c|c|}
\hline & No. & Percentage \\
\hline Babies transferred to NICU & 13 & 18.57 \\
\hline Neonatal death & 4 & 30.77 \\
\hline Went home alive & 9 & 69.23 \\
\hline \multicolumn{3}{|c|}{$\begin{array}{l}\text { Table 3: Incidence of Perinatal Mortality and } \\
\text { Morbidity in the Babies Transferred to NICU }\end{array}$} \\
\hline
\end{tabular}

\begin{tabular}{|c|c|c|c|c|}
\hline & NND & $\begin{array}{c}\text { Went Home } \\
\text { Alive }\end{array}$ & Total & Percentage \\
\hline $\begin{array}{c}\text { Low } \\
\text { Apgar }\end{array}$ & 3 & 3 & 6 & 46.15 \\
\hline $\begin{array}{c}\text { Normal } \\
\text { Apgar }\end{array}$ & 1 & 6 & 7 & 53.85 \\
\hline TOTAL & $\mathbf{4}$ & $\mathbf{9}$ & $\mathbf{1 3}$ & \\
\hline \multicolumn{5}{|c|}{ Xable 4: Incidence of Low Apgar } \\
in Babies Transferred to NICU
\end{tabular}

\begin{tabular}{|c|c|c|c|}
\hline AFI on Admission & Total & CS & VD \\
\hline$\leq 5 \mathrm{~cm}$ & $51(72.85 \%)$ & 31 & 20 \\
\hline$>5 \mathrm{~cm}$ & $19(27.14 \%)$ & 5 & 14 \\
\hline \multicolumn{3}{|c|}{$\mathrm{X}^{2}=5.28, \mathrm{df}=1, \mathrm{P}<0.05$} \\
\hline Table 5: Comparison of CS \& VD with Borderline \& \\
Moderate-to-Severe Oligohydramnios \\
\hline
\end{tabular}

\begin{tabular}{|c|c|c|c|}
\hline $\begin{array}{c}\text { Gestational } \\
\text { Age }\end{array}$ & Total & $\begin{array}{c}\text { Perinatal } \\
\text { Death }\end{array}$ & $\begin{array}{c}\text { Went Home } \\
\text { Alive }\end{array}$ \\
\hline$<37$ & $34(48.57 \%)$ & 7 & 27 \\
\hline$>37$ & $36(51.42 \%)$ & 0 & 36 \\
\hline \multicolumn{4}{|c|}{$\mathrm{X}^{2}=6.11, \mathrm{df}=1, \mathrm{P}<0.05$} \\
\hline \multicolumn{3}{|c|}{ Table 6: Gestational Age and Perinatal Outcome } \\
\hline
\end{tabular}

\section{DISCUSSION}

Though oligohydramnios alone is poor predictor of perinatal outcome, it is frequently used. So assessment of amniotic fluid volume is helpful to determine at risk pregnancies. Casey and Coworker. ${ }^{(9)}$ found an incidence of oligohydramnios of $2.3 \%$ in over 6400 pregnancies. Among these 6400 pregnancies, 147 women with oligohydramnios at 34 weeks of gestation, $5 \%$ LSCS for abnormal foetal heart rate, $1 \%$ meconium aspiration, 7\% NICU admission, 14/1000 stillbirth, 5\% neonatal death, $24 \%$ IUGR. This study has no obvious relation of oligohydramnios and meconium stained amniotic fluid; oligohydramnios and LSCS for foetal distress.

In our study $54 \%$ of patients required LSCS, $\mathrm{P}<0.05$; most common indication being foetal distress (34\%) Table 2 . Chauhan et al $(10,11,12)$ found that oligohydramnios $\mathrm{AFI}<5 \mathrm{~cm}$ is associated with LSCS for foetal distress and increased incidence of low Apgar score, i.e. Apgar at 5 min $<7 / 10$.

Sarno (1989-1990).(13,14) found that AFI $\leq 5 \mathrm{~cm}$ is associated with 5 fold increase in LSCS. Oligohydramnios is associated with variable decelerations in CTG, meconium stained amniotic fluid and low Apgar.(15,16) Usher RH et al found that the increase in foetal distress and meconium aspiration in post-term pregnancies without increase in birth asphyxia or foetal death, may reflect greater responsiveness of more mature foetus to mild asphyxic insults.(17); however finding of this study could not justify increased foetal monitoring in post-date pregnancies. Golan.(18) reported low Apgar score at $5 \mathrm{~min}$ in $4.5 \%$. In our study, it is $8.5 \%$.

Garmel.(19) (1997) observed that appropriately grown fetuses associated with oligohydramnios prior to 37 weeks have a significant 3 fold increase in pre-term birth, but no IUGR or IUD and incidence of NICU admission 19\%, which is $18.5 \%$ in our study which is more due to very low birth weight (5.7\%).

We found $10 \%$ perinatal death (3 IUFD, 4 NND). Still birth and NND are equal in 36- 40 weeks group, whereas NND is more in preterm group.

R. Gawri (JIPMER, Pondicherry).(20,21) studied role of antepartum amnioinfusion in raising AFI. Out of 8,5 succeeded but perinatal outcome remains poor.

There was a patient with AFI 1 at 35 weeks, who had received transabdominal amnioinfusion and baby went home alive. There were $20 \%$ IUGR babies in severe oligohydramnios with AFI $\leq 2 \mathrm{~cm}$ as compared to mild-tomoderate group. 


\section{CONCLUSION}

- Determination of AFI can be used as an adjunct to other foetal surveillance methods. It helps to identify those infants at risk of poor perinatal outcome.

- Gestational age, severity of oligohydramnios and associated IUGR are important criteria for perinatal outcome.

- In our circumstances where we have good neonatal intensive care units, prognosis of IUGR as well as very low birth weight babies is good.

- The term babies with oligohydramnios with no other associated complications do have better prognosis.

- Oligohydramnios with associated IUGR is poor predictor of peripartum complication.

- Recent management of oligohydramnios, such as amnioinfusion is yet to prove their benefit. In our circumstances where we have good neonatal intensive care units, prognosis of IUGR as well as very low birth weight babies is good.

\section{REFERENCES}

1. Dutta DC. A text book of Obstetrics including perinatology \& contraception. $6^{\text {th }}$ edn:p 218.

2. Phelan JP, Ahn MU, Smith CV, et al. Amniotic fluid measurement during pregnancy. J Reprod Med 1987;32:601-4.

3. Phelan JP, Smith CV, Small M, et al. Amniotic fluid volume assessment with four quadrant technique at 36 42 weeks of gestation. J Reprod Med 1987;32(7):540-2.

4. Elizabeth G Voxman, Susan Tran, Deborah A Wing. Low amniotic fluid index as a predictor of adverse perinatal outcome. Journal of perinatology 2002;22(4):282-5.

5. Lawrence Leeman, David A. Isolated oligohydramnios at term: is induction indicated? The J Family Practice 2005;54(1):25-32.

6. Zhang J, Trorndle J, Meikle S, et al. Isolated oligohydramnios is not associated with adverse outcome. BJOG 2004;111(3):220-5.

7. Magann EF, Sanderson M, Martin JN, et al. The amniotic fluid index, single deepest pocket, and two diameter pocket in normal human pregnancy. Am J Obstet Gynaecol 2000;182(6):1581-8.

8. Moore TR. Clinical assessment of amniotic fluid. Clin Obstet Gynaecol 1997;40(2):303-13.

9. Casey BM, McIntire DD, Bloom SL, et al. Pregnancy outcomes after antepartum diagnosis of oligohydramnios at or beyond 32 weeks of gestation. Am J Obstet Gynaecol 2000;182(4):909-12.
10. Chauhan SP, Sanderson M, Magann EF, et al. Perinatal outcome amniotic fluid index in antepartum and intra partum periods: a meta-analysis. Am J Obstet Gynaecol 1999;181(6):1473-8.

11. Chauhan SP, Washburne JF, Magann EF, et al. A randomized study to assess amniotic fluid index as a foetal admission test. Am J Obstet Gynaecol 1995;86(1):9-13.

12. Magann EF, Kinsella JM, Chauhan SP, et al. Does an amniotic fluid index of $<5$ necessitate delivery in high risk pregnancies? A case control study. Am J Obstet Gynaecol 1999;181:1473-8.

13. Sarno AP, Ahn MO, Brar HS, et al. Intrapartum doppler velocimetry, amniotic fluid volume and foetal heart rate as prediction of subsequent foetal distress. I. An initial report. Am J Obstet Gynaecol 1989;161(6 Pt 1):1508-14.

14. Sarno AP, Ahn MO, Phelan JP. Intrapartum amniotic fluid volume at term: association of ruptured membranes oligohydramnios and increased foetal risk. J Reprod Med 1990;35(7):719-23.

15. Shenker L, Reed KL, Anderson CF, et al. Significance of oligohydramnios complicating pregnancies. Am J Obstet Gynaecol 1991;164(6 Pt 1):1597-9.

16. Steer PJ, Eigbe F, Lissauer TJ, et al. Interelationship among cardiotocograms in labour, meconium stained amniotic fluid, arterial blood pH and Apgar score. Am J Obstet Gynaecol 1989;74(5):715-21.

17. Usher RH, Boyd ME, McLean FH, et al. Assessment of foetal risk in post-dated pregnancies. Am J Obstet Gynaecol 1988;158(2):259-64.

18. Golan A, Lin G, Evron S, et al. Oligohydramnios: maternal complication and foetal outcome in 145 cases. Gynaecol Obstet Invest 1994;37(2):91-5.

19. Garmel SH, Chelmow D, Sha SJ, et al. Oligohydramnios in appropriately grown fetus. Am J perinatol 1997;14(6):359-63.

20. Pierce J, Gaudiar FL, Sanchez-Ramos L. Intra partum amnioinfusion for meconium stained fluid: metaanalysis of prospective clinical trials. Am J Obstet Gynaecol 2000;95(6 Pt 2):1051-6.

21. Wenstorm K, Andrews WW, Maher JE. Amnioinfusion survey: prevalence, protocol and complication. Am J Obstet Gynaecol 1995;86(4 Pt 1):572-6. 